\title{
Peripherally induced oromandibular dystonia
}

\author{
Charulata Sankhla, Eugene C Lai, Joseph Jankovic
}

\begin{abstract}
Objectives-Oromandibular dystonia (OMD) is a focal dystonia manifested by involuntary muscle contractions producing repetitive, patterned mouth, jaw, and tongue movements. Dystonia is usually idiopathic (primary), but in some cases it follows peripheral injury. Peripherally induced cervical and limb dystonia is well recognised, and the aim of this study was to characterise peripherally induced OMD. Methods-The following inclusion criteria were used for peripherally induced OMD: (1) the onset of the dystonia was within a few days or months (up to 1 year) after the injury; (2) the trauma was well documented by the patient's history or a review of their medical and dental records; and (3) the onset of dystonia was anatomically related to the site of injury (facial and oral).
\end{abstract}

Results-Twenty seven patients were identified in the database with OMD, temporally and anatomically related to prior injury or surgery. No additional precipitant other than trauma could be detected. None of the patients had any litigation pending. The mean age at onset was $\mathbf{5 0 . 1 1}$ (SD 14.15) (range 23-74) years and there was a 2:1 female preponderance. Mean latency between the initial trauma and the onset of OMD was 65 days (range 1 day-1 year). Ten (37\%) patients had some evidence of predisposing factors such as family history of movement disorders, prior exposure to neuroleptic drugs, and associated dystonia affecting other regions or essential tremor. When compared with 21 patients with primary OMD, there was no difference for age at onset, female preponderance, and phenomenology. The frequency of dystonic writer's cramp, spasmodic dysphonia, bruxism, essential tremor, and family history of movement disorder, however, was lower in the posttraumatic group $(p<0.05)$. In both groups the response to botulinum toxin treatment was superior to medical therapy $(p<0.005)$. Surgical intervention for temporomandibular disorders was more frequent in the post-traumatic group and was associated with worsening of dystonia.

Conclusion-The study indicates that oromandibular-facial trauma, including dental procedures, may precipitate the onset of OMD, especially in predisposed people. Prompt recognition and treatment may prevent further complications. (f Neurol Neurosurg Psychiatry 1998;65:722-728)

Keywords: oromandibular dystonia; peripheral trauma; bruxism; dental surgery; botulinum toxin
Peripheral trauma has been implicated as a cause or a predisposing factor in various neurological disorders ${ }^{1-3}$ and in various movement disorders such as Parkinson's disease and tremors, ${ }^{4}$ dystonia, ${ }^{5-13}$ painful legs and moving toes, ${ }^{14}$ and myoclonus ${ }^{15}$ The relation between trauma and the subsequent development of a movement disorder, particularly dystonia and tremor, has been documented in many reports. $^{4-15}$

Oromandibular dystonia (OMD) is a focal dystonia involving the mouth, jaw, and tongue causing involuntary mouth closure or opening, deviation of the jaw, facial grimacing, or tongue movements. It often interferes with chewing, swallowing, and speaking. In addition, its appearance is often socially embarrassing and cosmetically disfiguring. When associated with dystonia of the upper face, such as blepharospasm, the term "cranial dystonia" is used ${ }^{16}$ The aetiology of OMD is usually unknown, but we describe 27 cases in whom the onset of the symptoms of OMD was anatomically and temporally related to a prior trauma to the face or mouth. To draw attention to this disabling disease, we characterised the clinical features of post-traumatic OMD and compared it with primary OMD.

Patients and methods

One hundred and sixty patients with OMD were identified from the database of 9083 patients evaluated at Baylor College of Medicine Parkinson's Disease Center and Movement Disorders Clinic over a period of 20 years from 1977 to 1996 . Twenty seven patients were identified as having peripherally induced, posttraumatic OMD using the following inclusion criteria: (1) the onset of the dystonia was within a few days or months (up to 1 year) after the injury; (2) the trauma was well documented by the patients' history or a review of their medical and dental records; and (3) the onset of dystonia was anatomically related to the site of injury (facial and oral). The exclusion criteria were: (1) secondary dystonia such as drug induced (tardive) dystonia, brain injury, Wilson's disease, and other recognised aetiologies of dystonia; (2) latency between the trauma and the onset of OMD was longer than 1 year; and (3) a strong psychogenic component. ${ }^{13}$ The degree of the peripheral trauma was categorised as follows: $1=$ mild injury causing discomfort but without obvious abrasion or bleeding; $2=$ minor trauma or surgery with abrasion or bleeding; $3=$ moderate trauma requiring $<1$ week of medical care; and $4=$ major or multiple trauma or surgery requiring $>1$ week of medical care. The severity of the patient's symptoms was categorised as follows: $0=$ normal; $1=$ slight disability without functional impairment; $2=$ moderate 
disability without functional impairment; $3=$ moderate disability with functional impairment (speaking/chewing/swallowing); and $4=$ incapacitated because of their inability to speak, chew, or swallow.

This group of patients with post-traumatic OMD was compared with a control group of 21 patients with primary (idiopathic) OMD randomly selected from our database of patients with primary (idiopathic) dystonia. Both groups of patients were compared for the following clinical variables: age at onset, duration of illness, type of movement disorder at onset, spread of symptoms and anatomical distribution, any potential predisposing factors, and response to various medications, including the number of medications, and response to botulinum toxin A (BTX-A) therapy. The response to various medications and to BTX-A therapy was assessed using a previously described clinical rating scale. ${ }^{17}$ The "peak effect" score, defined as the maximum benefit after the injection, was rated on a $0-4$ scale based on the information provided by the patients, daily diary of their symptoms, and interview of the spouse or friends $(0=$ no effect; $1=$ mild improvement; 2 =moderate improvement; $3=$ moderate improvement in severity and function; and $4=$ marked improvement in severity and function). In the post-traumatic group the following variables were also analysed: injury and disability rating, the correlation between the severity of the injury and severity of the OMD, and latency between trauma and the first appearance of OMD. The additional information was obtained by a questionnaire and a structured personal or telephone interview of the patients and their family members.

STATISTICAL ANALYSIS

The results of the response to medical and BTX-A therapy in both post-traumatic and primary groups were compared for significance using the two tailed Fisher's exact test. We compared both forms of the treatments for functional improvement scores (3-4) and no functional improvement (scores $0-2$ ). Fisher's exact test was also used to determine the significance of the differences in the various clinical parameters seen in these two groups. The computer software used comprised SAS computer software by SAS Institute Inc, Cary, NC, USA, and Astute DDU Software, University of Leeds, Leeds, UK.

\section{ILLUSTRATIVE CASES}

Patient 1

This 61 year old woman underwent a series of dental procedures such as gingivectomy and braces for six months in 1979. Afterwards, she had cosmetic filling of her maxillary teeth followed by placement of three separate bridges. On the same day of this last procedure she noticed abnormal jaw movements which caused displacement of the left bridge. Since that time she has been unable to wear her lower dentures. Her mouth and jaw movements worsened gradually over the next 16 years. The patient also had mouth soreness on wearing her dentures and had difficulty in speaking clearly due to the painful spasms. Four years before our evaluation, her movements occurred only while wearing dentures and completely resolved within 30 minutes of their removal. The movements could be relieved by sensory tricks such as touching her tongue to the top of her mouth, biting her lips and, swallowing. The patient has been seen during the past 16 years by various dentists and physicians, without any medications being prescribed or a working diagnosis made.

Examination disclosed repetitive deviation of the mandible to the left, particularly when speaking and chewing. She had bilateral masseter spasms and considerable difficulty in moving her jaw to the right, particularly when the upper dentures were in place. She was injected with 195 units of BTX-A over two sessions and experienced dramatic relief of her symptoms (grade 4 improvement) for about 4 months during which she was able to wear her dentures without any discomfort.

\section{Patient 2}

This 42 year old woman had dentures fitted and correction of her overbite. She started adjusting her bite to get used to her new dentures. Three days after she started to use the dentures she noted difficulty in closing her mouth and experienced involuntary protrusion of her tongue. This worsened when she attempted to eat and she was able to tolerate only pureed diet. She stopped wearing her lower dentures due to involuntary tongue protrusion and her inability to close her mouth. She used sensory tricks such as pulling her face up with a finger, which enabled her to eat, but still had difficulty in swallowing. She developed right temporomandibular joint pain and popping of the joint. She was treated with trihexyphenidyl, which helped her spasms but she continued to have difficulty in eating. Examination in the resting position disclosed that she had $6-7 \mathrm{~Hz}$ frequency jaw tremors with lip pursing movements. Her jaw was deviated to the right. On opening her mouth she had rhythmical movements of her tongue and she had considerable difficulty in closing her jaw. An attempt to eat resulted in protrusion of her tongue, which kept pushing her food out and she was unable to close her mouth because of drawing of her chin and lower jaw downward and backwards. She had considerable difficulty in swallowing. In addition to OMD, she also had associated involuntary contraction of the corrugator, frontalis, and orbicularis oculi muscles with blepharospasm while eating.

Injections of BTX-A into the submental muscles on two occasions (25, 50 units) provided a grade 3 improvement. She is now able to eat, but still has difficulty closing her mouth when she drinks.

\section{Results}

Twenty seven patients ( 18 women) fulfilled the inclusion criteria for post-traumatic dystonia (table 1). The average age at onset of dystonia was 50.11 (SD 14.15) (range 16-73) years with a peak between 50 to 60 years of age. The 
Table 1 Clinical features of patients with peripherally induced OMD

\begin{tabular}{|c|c|c|c|c|c|c|c|c|}
\hline No & $\begin{array}{l}\text { Age at } \\
\text { onset/ } \\
\text { sex }\end{array}$ & Type of injury & $I R$ & $D R$ & $\begin{array}{l}\text { Latency } \\
\text { (days) }\end{array}$ & Dystonia at onset & Dystonia at present & Possible predisposing factors \\
\hline 1 & $73 / \mathrm{F}$ & Ill fitting dental bridge & 1 & 2 & 7 & SD & $\mathrm{SD}, \mathrm{OMD}$, cranial & $\begin{array}{l}\text { Essential tremor for } 20 \mathrm{y}, \mathrm{h} / \mathrm{o} \text { WC, } \\
\text { family history of tremor and TS }\end{array}$ \\
\hline 2 & $44 / \mathrm{F}$ & Gingivectomy followed by braces & 3 & 3 & 1 & OMD & OMD & None \\
\hline 3 & $42 / \mathrm{F}$ & Splint in TMJ & 1 & 4 & 7 & OMD & $\mathrm{OMD}, \mathrm{CD}$ & \\
\hline 4 & $56 / \mathrm{F}$ & $\begin{array}{l}\text { Multiple dental procedures, new } \\
\text { dentures }\end{array}$ & 2 & 3 & 14 & $\mathrm{OMD}$ & $\mathrm{CD}, \mathrm{OMD}$ & Edentulous state for $5 \mathrm{y}$ \\
\hline 5 & $37 / \mathrm{F}$ & Facial trauma & 2 & 3 & 56 & Cranial, OMD, CD & $\begin{array}{l}\text { Cranial, OMD, } \\
\text { CD }\end{array}$ & \\
\hline 6 & $42 / \mathrm{F}$ & Root canal treatment & 2 & 3 & 7 & $\mathrm{CD}, \mathrm{OMD}$ & $\mathrm{CD}, \mathrm{OMD}$ & $\begin{array}{l}\text { Previous CD, h/o haloperidol } \\
\text { exposure to treat her CD }\end{array}$ \\
\hline 7 & $39 / \mathrm{F}$ & $\begin{array}{l}\text { Extraction of the lower molar with } \\
\text { institution of plates }\end{array}$ & 3 & 3 & 112 & OMD & OMD & \\
\hline 8 & $70 / \mathrm{F}$ & Surgery on left gum & 3 & 2 & 5 & OMD & OMD & $\mathrm{H} \backslash$ o nerve pill 20 years ago \\
\hline 9 & $58 / \mathrm{F}$ & Oral surgery & 3 & 4 & 10 & Lingual & $\begin{array}{l}\text { Cranial, OMD, } \\
\text { CD }\end{array}$ & $\begin{array}{l}\text { Bell's palsy } 7 \text { years ago, trigeminal } \\
\text { neuralgia }\end{array}$ \\
\hline 10 & $62 / \mathrm{M}$ & Oral and facial trauma & 4 & 3 & 180 & OMD & $\mathrm{OMD}, \mathrm{CD}$ & \\
\hline 11 & $37 / \mathrm{F}$ & $\begin{array}{l}\text { Maxillary and mandibular } \\
\text { osteotomy }\end{array}$ & 4 & 4 & 120 & $\begin{array}{l}\text { OMD (unilateral jaw } \\
\text { dystonia) }\end{array}$ & $\mathrm{OMD}$ & \\
\hline 12 & $53 / \mathrm{F}$ & $\begin{array}{l}\text { Ill fitting dentures, dentures } \\
\text { implant }\end{array}$ & 1 & 3 & 14 & $\mathrm{OMD}$ & OMD & \\
\hline 13 & $59 / \mathrm{M}$ & $\begin{array}{l}\text { Root canal treatment, tooth } \\
\text { extraction, apioctemy }\end{array}$ & 2 & 4 & 7 & OMD & OMD & \\
\hline 14 & $62 / \mathrm{M}$ & Frontal sinus obliteration & 3 & 3 & 150 & OMD & OMD & \\
\hline 15 & $39 / \mathrm{F}$ & New dentures with correction & 1 & 4 & 3 & OMD & OMD, cranial & \\
\hline 16 & $47 / \mathrm{F}$ & $\begin{array}{l}\text { MVA with injury to chin and jaw, } \\
\text { loss of teeth and broken dental } \\
\text { plate }\end{array}$ & 3 & 2 & 42 & OMD & $\mathrm{OMD}, \mathrm{CD}$ & \\
\hline 17 & $71 / \mathrm{M}$ & $\begin{array}{l}\text { Gum infection with total dental } \\
\text { extraction }\end{array}$ & 3 & 4 & 1 & OMD & OMD & \\
\hline 18 & $16 / \mathrm{M}$ & $\begin{array}{l}\text { Gum surgery on upper and lower } \\
\text { gum }\end{array}$ & 3 & 2 & 4 & $\mathrm{OMD}$ & OMD & Facial and abdominal tics \\
\hline 19 & $55 / \mathrm{F}$ & New braces & 1 & 3 & 270 & Lingual & $\begin{array}{l}\mathrm{OMD}, \mathrm{CD} \\
\text { cranial }\end{array}$ & $\begin{array}{l}\text { Face lift } 9 \text { years ago, rt hypoglossal } \\
\text { palsy }\end{array}$ \\
\hline 20 & $60 / \mathrm{F}$ & Crowning of upper molar & 1 & 3 & 14 & Facial & $\begin{array}{l}\mathrm{OMD}, \mathrm{CD} \\
\text { cranial }\end{array}$ & \\
\hline 21 & $60 / \mathrm{F}$ & $\begin{array}{l}\text { Right TMJ arthroscopic surgery } \\
\text { with breaking of adhesion. Joint } \\
\text { manipulation, TMJ splint }\end{array}$ & 3 & 4 & 3 & OMD & $\mathrm{OMD}$ & Facial tics \\
\hline 22 & $68 / M$ & $\begin{array}{l}\text { Root canal treatment molar } \\
\text { extraction, placement of upper } \\
\text { partials }\end{array}$ & 2 & 3 & 90 & OMD & OMD & \\
\hline 23 & $24 / \mathrm{M}$ & MVA facial injury & 4 & 3 & 365 & $\mathrm{SD}, \mathrm{OMD}$ & $\begin{array}{l}\text { OMD, SD, CD, } \\
\text { WC }\end{array}$ & $\begin{array}{l}\text { Delayed milestones with } \\
\text { stereotypies }\end{array}$ \\
\hline 24 & $50 / \mathrm{M}$ & Replacement of the cap & 2 & 3 & 7 & OMD & $\mathrm{OMD}, \mathrm{CD}$ & $\mathrm{Fx} \mathrm{h} / \mathrm{o}$ of tremor \\
\hline 25 & $33 / \mathrm{F}$ & Facial and jaw injury & 3 & 2 & 7 & OMD & OMD & \\
\hline 26 & $56 / \mathrm{F}$ & $\begin{array}{l}\text { New dentures which did not fit } \\
\text { well }\end{array}$ & 1 & 3 & 30 & OMD & OMD & \\
\hline 27 & $40 / \mathrm{M}$ & Facial injury by football & 1 & 3 & 224 & OMD, CD, cranial & $\begin{array}{l}\text { OMD, CD, } \\
\text { cranial }\end{array}$ & ET \\
\hline
\end{tabular}

$\mathrm{F}=$ female; $\mathrm{M}=$ male; $\mathrm{CD}=$ cervical dystonia; $\mathrm{SD}=$ spasmodic dysphonia; WC=writer's cramp; $\mathrm{ET}=$ essential tremor; TS=Tourette's syndrome; IR=injury rating $0=4$; $\mathrm{DR}=$ disability rating $0-4$ ( described earlier); $\mathrm{MVA}=$ motor vehicle accident; $\mathrm{TMJ}=$ temporomandibular joint; $\mathrm{h} / \mathrm{o}=\mathrm{history}$ of.

average duration of symptoms from onset to the patient's initial assessment at our clinic was 5.19 (SD) 3.86 (range 1-16) years. Four patients $(5,10,23$, and 27$)$ had trauma involving their face or oral and dental structures. One patient (14) had frontal sinus obliteration. The remaining 22 patients had had at least one dental procedure before the onset of the OMD. The mean latency between the initial insult and the onset of the dystonia was 65 (SD 94) (range 1-365) days. Twelve patients had the onset of their symptoms within 1 week after trauma including two patients ( 2 and 17) who noticed the initial symptoms on the same day of the trauma. Most of our patients underwent extensive dental work before and after the onset of their symptoms with injury rating of 3 in 10 patients, and 4 in three (average 2 (SD 1). Four patients $(4,12,15$, and 26$)$ had ill fitting dentures and one (1) had an ill fitting dental bridge. These patients gave a history of trying to adjust their bite by manipulating the jaw to adapt to the newly fitted dentures or the bridge. These manipulations and procedures were made before the onset of jaw spasms in all cases. There was no correlation between the injury grading and subsequent disability and severity of the dystonia (table 1 ).

All patients had symptoms predominantly involving the oromandibular region. The onset of symptoms was in the oromandibular region in 21 patients. One of these patients (11) had unilateral jaw spasms which progressed to OMD. Symptoms began as spasmodic dysphonia in two patients, in the tongue region in two, and in the face in one. One patient (6) had preexisting cervical dystonia and the symptoms spread to the oromandibular region within 1 week after root canal treatment and 1 year after the onset of her cervical dystonia. The spread of the symptoms to cervical and cranial (facial and blepharospasm) region was noted in 52\% of patients.

Of the 27 patients, 10 (37\%) had possible predisposing factors which may have made them more prone to developing dystonia after injury. Two patients (1 and 27) had essential tremor, two (1 and 24) had a positive family history of essential tremor, and one had associated tics consistent with the diagnosis of 
Table 2 Comparison of primary and post-traumatic OMD

\begin{tabular}{lll}
\hline Variables & Primary & Post-traumatic \\
\hline Sex F/M & $15 / 6$ & $18 / 9$ \\
Duration of symptoms when first seen (y): & 3.62 & 5.19 \\
$\quad$ Mean & 3.18 & 3.86 \\
SD & $1-12$ & $1-16$ \\
Range & & \\
Age at onset (y): & 51.48 & 50.11 \\
Mean & 12.51 & 14.15 \\
SD & $23-74$ & $16-73$ \\
Range & & $12(44)$ \\
Associated movement disorders (n (\%)): & $7(33)$ & $8(30)$ \\
Cervical dystonia & $7(33)$ & $1(4)^{\star}$ \\
Blepharospasm & $6(29)$ & $2(7)^{\star}$ \\
Writer's cramp & $8(38)$ & $2(7)$ \\
Spasmodic dysphonia & $3(14)$ & $9(33)$ \\
Essential tremor & $7(33)$ & $14(52)$ \\
Sensory tricks & $6(29)$ & $2(7)^{\star}$ \\
Pain & $7(33)$ & $4(15)$ \\
Family history of MD & $7(33)$ & \\
Bruxism &
\end{tabular}

${ }^{\star} \mathrm{p}<0.05 . \mathrm{F}=$ female; $\mathrm{M}=$ male; $\mathrm{MD}=$ movement disorder.

Tourette's syndrome. One patient was edentulous before placement of the dentures, but had no history suggestive of edentulous dyskinesia. She developed her symptoms 14 days after the placement of new dentures. One patient (6) had pre-existing cervical dystonia and had received haloperidol as a treatment for her cervical dystonia. Other conditions that may have predisposed these patients to peripherally induced OMD included possible exposure to neuroleptic drugs 10 years before the onset of dystonia, a history of tics, hypoglossal palsy, and a history of cosmetic facial surgery, Bell's palsy, trigeminal neuralgia, and delayed developmental milestones. As none of these possible predisposing factors have been validated, with the possible exception of family history of tremor, their relevance, if any, to the aetiology of dystonia in these patients is unknown.

Four patients (6, 9, 21, and 25) developed nocturnal bruxism after the onset of OMD with family history of bruxism in one (21). Three of these patients (21 and 25) also had diurnal bruxism. Five patients (3, 11, 15, 21, and 25) had associated temporomandibular joint symptoms; two (15 and 25) after the onset of their OMD. Three patients had temporomandibular joint symptoms before the onset of OMD. Two patients ( 3 and 21) had a temporomandibular joint syndrome, the treatment of which might have triggered the onset of OMD. One of these two had a temporomandibular joint splint and the other had temporomandibular joint arthroscopy before the onset of OMD. Three of the patients had extensive oral and temporomandibular joint surgery with worsening of their OMD after each intervention.

We compared this group of patients with post-traumatic OMD with 21 randomly selected patients (15 women) with primary OMD from our database as a control group. Their mean age at onset was 51.48 (SD 2.51) (range 23-74) years. The average duration of symptoms from the onset to our initial evaluation was 3.62 (SD 3.18) (range 1-12) years. Three patients had the onset of their dystonia in the cervical region, four had spasmodic dysphonia at onset, whereas two patients had their symptoms at onset in the cranial region. Seven patients had bruxism and four patients had temporomandibular joint symptoms.

There was no difference in any of the clinical variables when the two groups of OMD were compared (table 2). Although associated pain was more frequent in the post-traumatic group than in the primary group, the difference did not reach significance. Both groups used sensory tricks to alleviate their dystonia to the same degree. The most common sensory trick used by patients in both groups was bending their neck forward, which enabled them to eat. Essential tremor was the most often associated movement disorder in primary OMD compared with post-traumatic OMD; however, this difference did not reach significance. A family history of movement disorders was notably less frequent in the post-traumatic group $(\mathrm{p}<0.05)$. The frequencies of spasmodic dysphonia $(p<0.05)$ and writer's cramp $(p<0.05)$ were less common in patients with post-traumatic OMD than in the primary OMD group. Associated bruxism was less frequent in post- traumatic than primary OMD, but this difference did not reach significance.

The phenomenology, including the presence of resting or action dystonia, was similar in both groups. The spread of the symptoms to a contiguous anatomical region seemed more rapid in the post-traumatic group than in the primary group, but these data were not available on all patients due to inability of the patients to recollect the details of the spread of the initial symptoms. The severity of the symptoms was more pronounced in post-traumatic than primary OMD; however, the comparison of the disability scores did not reach significance.

Both groups received medical treatment and BTX-A injections. The average number of medications used in the post-traumatic group was four per patient and in the primary group three per patient. In the post-traumatic group 12 patients received trihexyphenidyl, which was the most commonly used drug. Baclofen and clonazepam were the next most common, used in six and seven patients respectively. The patients with jaw opening OMD received BTX-A injections in the submentalis complex whereas patients with jaw closing dystonia were predominantly injected in the masseters. In 21 patients who received BTX-A, nine $(43 \%)$ had no functional improvement (scores 0,1 , and 2) and $12(57 \%)$ patients had functional improvement (scores 3 and 4). In the primary group, 19 patients received BTX-A therapy. Six (32\%) of these had no functional improvement, but 13 $(68 \%)$ reported meaningful functional improvement. We compared the results to medical treatment using the same criteria and Fisher's exact test. The results indicated BTX-A therapy to be superior to the various forms of the medical treatment $(p<0.005)$ in both groups. Five patients in the post-traumatic group and 11 in the primary group had complications after their first injections such as jaw weakness, loss of smile, dysphagia, nasal regurgitation, and jaw tremor. These complications were not seen with dose adjustment and improved techniques in subsequent treatment sessions. 
Table 3 Summary of studies of post-traumatic oromandibular dystonia

\begin{tabular}{lllll}
\hline Author/year & Nature of the trauma & Patients $(n)$ & Latency (days) & Possible predisposing factors \\
\hline Sutcher et al $1971^{20}$ & Ill fitting dentures & 4 & Not known & Loss of proprioception \\
Jankovic and Van der Linden $1985^{5}$ & Facial trauma & 1 & 12 Months & Developmental delay \\
Koller et al $1983^{21}$ & Dental extraction & Not known & Not known & None \\
Thompson et al $1986^{18}$ & Dental & 1 & Not known & None \\
Brin et al $1986^{23}$ & Oral surgery & 2 & 3 Days to a week & Not known \\
Present study & Orofacial trauma & 27 & 65 Days & Family history of movement disorder, prior exposure to \\
& & & & neuroleptics, associated dystonia, essential tremor. \\
\hline
\end{tabular}

\section{Discussion}

Oromandibular dystonia is a focal dystonia which causes involuntary mouth closure or opening, deviation of the jaw, facial grimacing, and tongue movements. It may be accompanied by involuntary closure of the eyes (blepharospasm), strained or breathy voice (spasmodic dysphonia), cervical dystonia, or other movement disorders. Often misdiagnosed as a "dental problem", "temporomandibular joint syndrome", "psychological disturbance", or "bruxism", OMD may cause considerable functional and psychosocial disability. ${ }^{16}$ The dystonia may be present only while eating and can be relieved by sensory tricks such as touching the face, pinching the neck, and bending the neck forward. The symptoms of OMD can be worsened by emotional factors, which is one of the reasons for the delay in the diagnosis. The cause of OMD is usually unknown (primary or idiopathic), but it may be associated with neuroleptic exposure, CNS trauma, hypoxic brain damage, metabolic disorders, and ischaemic or demyelinating lesions in the upper brain stem. ${ }^{18}$ Rarely, peripheral trauma can induce dystonia. Although the concept of peripherally induced dystonia was first met with some skepticism, the notion that local trauma can lead to dystonia of the involved body part, sometimes also referred to as the dystonia-causalgia syndrome, is now well accepted. ${ }^{4-15}$ Peripherally induced dystonia, however, is often not recognised, particularly if the trauma is relatively trivial or the latency between trauma and the onset of dystonia is longer than a few days.

The clinical features of peripherally induced OMD in our series were similar to those of primary OMD, with a few exceptions. Severity of symptoms and progression of the disease were more prominent in the post-traumatic group. Frequency of associated movement disorders such as essential tremor, bruxism, writer's cramp, and spasmodic dysphonia was lower in the post-traumatic group than in the patients with primary $O M D$, but the difference was significant only for writer's cramp and spasmodic dysphonia (table 2). Post-traumatic OMD had a lesser tendency to spread to contiguous or non-contiguous segments when compared with primary OMD. Family history of movement disorders was also less frequent in the post-traumatic group $(7 \%)$ than the primary group $(33 \%)(p<0.05)$. These data, however, must be interpreted cautiously because of the few cases in each group. The use of sensory tricks to relieve the dystonia was seen in both groups. This is by contrast with the usual absence of sensory tricks in other posttraumatic dystonias, such as cervical dystonia. ${ }^{19}$
Peripherally induced OMD has received little attention in the neurologial and dental literature and its true prevalence is unknown. In 1971, Sutcher et $a l^{20}$ described four patients who developed jaw opening OMD after obtaining ill fitting dentures. Their patients had worn these dentures from a minimum of 1 year to many years before noticing the abnormal mouth movements. In our series four patients had new sets of dentures, including one patient with an ill fitting dental bridge. The patients with ill fitting dentures had a history of manipulating their jaw position using their jaw muscles to get used to the new dentures. These malaligned dentures may have caused an impairment of proprioception of the oral cavity leading to subsequent development of dystonia or so-called "edentulous dyskinesia". ${ }^{20}{ }^{21}$ We included one patient with OMD after facial injury in our original series of patients with peripherally induced dystonia. ${ }^{5}$ In a series of patients with unilateral jaw and hemimasticatory spasms, Thompson et $a l^{22}$ described a 42 year old woman who developed unilateral jaw dystonia after a dental extraction similar to that of our patients. Brin et $a l^{23}$ briefly reported a series of 23 patients with post-traumatic limb, axial, cervical, spasmodic dysphonia, and generalised dystonia and included two patients with OMD after oral surgery. Koller et $a l^{6}$ in their review of post-traumatic movement disorders described patients developing OMD after tooth extraction, but did not provide any details about the latency between the dental work and subsequent development of dystonia (table 3).

Our study shows that OMD can occur after an injury, oro-mandibular surgery, or a dental procedure. Although the relation between such insults and the subsequent development of OMD may be purely coincidental, the temporal and anatomical association, however, argues in favour of a cause and effect relation. Fourteen of our patients, eight with cranial dystonia before trauma and six with spread to cranial structures beyond the oromandibular region, may possibly have had or were significantly predisposed to developing cranial dystonia and the trauma may have exacerbated or precipitated the onset. Various predisposing factors, such as an associated movement disorder, family history of tremors, edentulous state, exposure to neuroleptic drugs, and peripheral nerve injury may contribute to the development of this movement disorder under some circumstances or in certain vulnerable people (table 3)..$^{50-23}$ Seven of our $27(26 \%)$ patients had possible predisposing factors such as a family history of movement disorders, prior exposure to neuroleptic drugs, delayed 
milestones, history of movement disorders such as cervical dystonia, essential tremor, and tics. ${ }^{45-27}$ It is not known, however, whether these factors play an important, or any, part in the mechanism of peripherally induced OMD. Fletcher $e t a l^{27}$ suggested that peripheral injury could trigger the onset of dystonia in genetically predisposed persons with primary generalised dystonia and that dystonia worsened after each subsequent injury. We made a similar finding in one of our patients who had preexisting cervical dystonia and developed OMD after root canal treatment. Three other patients noted exacerbation of their OMD after repeat oral surgeries. No correlation between the severity of the trauma and subsequent development of dystonia was established in our study (table 1).

A causative relation between peripheral injury and subsequent dystonia has been difficult to establish experimentally and there is no animal model that adequately mimics the clinical syndrome. Some experimental studies, however, suggest that peripheral injury can lead to reorganisation at cortical, subcortical, and spinal cord level resulting in motor dysfunction. The relation between peripheral trauma, pain, dystonia, and the frequent association with reflex sympathetic dystrophy further supports the notion that pathways subserving pain and those involved in motor control are important for peripherally induced movement disorders. ${ }^{5-12}$ Direct demonstration of a relation between pain and basal ganglia came from de Ceballos et al. ${ }^{28}$ They showed that a thermal injury to one hind limb in rats resulted in a delayed onset withdrawal of the affected limb and this was associated with a marked reduction of met-enkephalin and leu-enkephalin concentration in the globus pallidum bilaterally and only met-enkephalin in the caudate and putamen. These changes were most pronounced contralateral to the injured limb. They considered that the peptide changes occurred in response to the injury and were responsible for the subsequent motor impairment. There are many other examples of cortical or subcortical reorganisation in response to altered peripheral sensory input. ${ }^{29} 30$ Further evidence for cortical changes after peripheral injury is the finding that patients with amputated limbs show larger motor evoked potentials and recruit a larger percentage of the motor neuron pool after transcortical stimulation in muscles proximal and ipsilateral to the amputated limb compared with the contralateral limb. ${ }^{31} 32$

Oromandibular dystonia, whether primary or post-traumatic, can lead to secondary complications. Bruxism, often associated with markedly increased dental wear, was more common in primary OMD (33\%) than in post-traumatic OMD (15\%), and $19 \%$ of our patients had associated temporomandibular joint syndrome, irrespective of the aetiology of the OMD. Therefore, to prevent these and other complications, prompt and appropriate treatment of OMD is important. Our findings suggest that OMD (primary and posttraumatic) responds poorly to various medica- tions commonly used to treat dystonia, such as trihexyphenidyl, baclofen, and clonazepam. Injections of BTX-A into the affected muscles, although usually effective, is sometimes complicated by dysphagia and jaw weakness. These complications were encountered in $19 \%$ of the patients with post-traumatic and in $52 \%$ of those with primary dystonia. The complication rate, however, can be minimised if the treating physician has a detailed knowledge of the anatomy of oromandibular muscles and is skilled and experienced in treating this form of dystonia.

Despite growing evidence supporting the relation between trauma and subsequent development of dystonia, the physiological and biochemical meachanisms of peripherally induced dystonia, including OMD, are not well understood. Our series broadens the range of peripherally induced movement disorders and draws attention to the often unrecognised posttraumatic OMD.

We express our gratitude to Dr Myrna Khan for her assistance with the statistical analysis. We thank Kenneth Schwarts and Jenny Beach for their technical assistance. We also thank the National Parkinson Foundation and the RSMIS Foundation for their generous support.

1 Tandan R, Bradley WG. Amyotrophic lateral sclerosis: part 2 etiopathogenesis. Ann Neurol 1985;18:419-31.

2 Miller H. Trauma and multiple sclerosis. Lancet 1964;i:84850.

3 Kondo K, Kuroiwa Y. A case control study of CreuztfeldJacob disease: association with physical injuries. Ann Neurol 1982;11:377-81.

4 Cordoso F, Jankovic J. Peripherally induced tremor and parkinsonism. Arch Neurol 1995;52:263-70.

5 Jankovic J, Van Der Linden C. Dystonia and tremor induced Jankovic J, Van Der Linden C. Dystonia and tremor induced
by peripheral trauma: predisposing factors. $\mathcal{F}$ Neurol Neurosurg Psychiatry 1985;51:1512-9.

6 Koller WC, Wong GF, Lang A. Posttraumatic movement disorders: a review. Mov Disord 1989;4:20-36.

7 Sheehy MP, Marsden CD. Trauma and pain in spasmodic torticollis. Lancet 1980;i:777-8.

8 Schott GD. Induction of involuntary movements by peripheral trauma: an analogy with causalgia. Lancet 1986;ii:712 16.

9 Schott GD. Mechanisms of causalgia and related clinical conditions. Brain 1986;109:717-38.

10 Schott GD. The relationship of peripheral trauma and pain to dystonia. F Neurol Neurosurg Psychiatry 1985;48:698701 .

11 Schwartzman RJ, Kerrigan J. The movement disorder of reflex sympathetic dystrophy. Neurology 1990;40:57-61

12 Bhatia KP, Bhatt MH, Marsden CD. The causalgiadystonia syndrome. Brain 1993;116:843-51.

13 Jankovic J. Post-traumatic movement disorders: central and peripheral mechanisms. Neurology 1994;12:2006-12.

14 Schott GD. Painful legs and moving toes: the role of trauma. f Neurol Neurosurg Psychiatry 1981;44:344-6.

15 Jankovic J, Pardo R. Segmental myoclonus: clinical and pharmacological study. Arch Neurol 1986;43:1025-30.

16 Jankovic J. Etiology and differential diagnosis of blepharospasm and oromandibular dystonia. In: Jankovic J, Tolosa E, eds. Focal dyskinesias. Advances in neurology. New York: Raven Press. 1988;49:103-16.

17 Jankovic J, Schwartz K. Clinical correlates of response to botulinum toxin injections. Arch Neurol 1991;48:1253-6.

18 Jankovic J, Fahn S. Dystonic syndromes. In: Jankovic J, Tolosa E, eds. Parkinson's disease and movement disorders. 2nd ed. Baltimore, MD: Williams and Wilkins, 1993;33774 .

19 Truong DD, Dubinsky R, Hermanowicz N, et al. Posttraumatic torticollis. Arch Neurol 1991;48:221-3

20 Sutcher HD, Underwood RG, Beatty RV, et al. Orofacial dyskinesia: a dental dimension. F $A M A$ 1971;216:1459-63.

21 Koller WC. Edentulous orodyskinesia. Ann Neurol 1983;13: 97-9.

22 Thompson PD, Obeso JA, Delgado G, et al. Focal dystonia of the jaw and differential diagnosis of unilateral jaw and masticatory spasms. F Neurol Neurosurg Psychiatry 1986;49: 651-6.

23 Brin MF, Fahn S, Bressman SB, et al. Dystonia precipitated by peripheral trauma [abstract]. Neurology 1986;36(suppl 1): 119 .

24 Burke RE, Fahn S, Jankovic J, et al. Tardive dystonia: late onset and persistent dystonia caused by antipsychotic onset and persistent dystonia caus
drugs. Neurology 1987;37:616-23.

25 Scott B, Jankovic J. Delayed-onset progressive movement disorders. Neurology 1996;46:68-74. 
26 Bratslavsky $M$, van der Eecken $H$. Altered synaptic organization in facial nucleus following facial nerve regeneration: an electrophysiological study in man. Ann Neurol 1977; 2:71-73.

27 Fletcher NA, Harding AE, Marsden CD The relationship between trauma and primary torsion dystonia. $\mathcal{F}$ Neurol Neurosurg Psychiatry 1991;54:713-7.

28 de Ceballos ML, Baker M, Rose S, et al. Do enkephalins in basal ganglia mediate a physiological motor rest mechanism? Mov Disord 1986;1:223-33.

29 Kaas JH, Florence SL, Jain N. Reorganization of sensory systems of primates after injury. Neuroscientist 1997;3:123-9.
30 Byle NN, Merzenich MM, Jenkins WM. A primate genesis model of focal dystonia and repetitive strain injury: I. Learning-induced dedifferntiation of the representation of the hand in the primary somatosensory cortex in adult monkeys. Neurology 1996;47:508-20.

31 Cohen LG, Bandinelli S, Findley TW, et al. Motor reorganisation after upper limb amputation in man. A study with focal magnetic stimulation. Brain 1991;114:615-27.

32 Knecht S, Henningsen H, Höhling C, et al. Plasticity of plasticity? Changes in the pattern of perceptual correlates of reorganization after amputation. Brain 1998;121:71724

\section{HISTORICAL NOTES}

\section{Early days of the tuning fork}

Neurologists have for many years used the tuning fork both as a crude test for hearing, by means of the classic tests of HA Rinne $(1819-1868)^{1-3}$ and Weber-Liel (1832-1891), and for vibration sense. In Pavia, Italy, G Cardano, astrologer, physician, and mathematician, in 1550 suggested that sound could be transmitted through the bony skull as well as through the air and a few years later, $H$ Capivacci, a physician in Padua, used this phenomenon as a means of differentiating between middle ear and nerve deafness. ${ }^{4}$ The technique was then used by a German physician G C Schelhammer in 1684 who used a simple table fork. But, the study of ear diseases was in its infancy and little progress was made for two centuries.

The tuning fork was invented in 1711 by a John Shore, trumpeter and lutanist to both Henry Purcell and George Frederick Handel in London. The tuning fork found a place as a musical instrument employed in the concert halls, churches, and chamber music ensembles throughout Europe. It started as a small steel instrument consisting of a stem with two stout flat prongs, which on being made to vibrate produced a musical note of constant pitch, thus serving as a standard for tuning musical instruments and in acoustic investigations. In 1799 Young observed": "The fundamental note was found to be one sixth of a tone higher than the respective octave of a tuningfork marked C"

E F F Chladni, a physicist in Wittenberg in about 1800 , first systematically studied the mode of vibration of the tuning fork with its nodal points. Using sets of tuning forks, he made a musical instrument that failed to achieve popularity. J H Scheibler in Germany in 1834 produced a set of 54 tuning forks with a range of $220 \mathrm{~Hz}$ to $440 \mathrm{~Hz}$, at $4 \mathrm{~Hz}$ intervals. In Paris, J Lissajous created a tuning fork with a resonance box, intended to represent the international standard of the note with 435 vibrations per second, but this too was not generally accepted. ${ }^{4} \mathrm{~K}$ R Koenig, a Parisian physicist, devised a clever clockwork mechanism which produced a continuous vibration and sound in the tuning fork. Hermann von Helmholtz in 1863 also used sets of electromagnetically powered tuning forks to elicit the sensations of tone. Until the electronic valve, the tuning fork was the only instrument that produced sinusoidal vibrations of standard duration.

Huizing ${ }^{67}$ has reviewed the early papers on tuning fork tests of deafness. He relates that in 1855 Rinne compared hearing by air and bone conduction, and used the tuning fork for the diagnosis of deafness. However, before Rinne, Polansky in 1842 gave a detailed but forgotten description of the test and of its application in deafness. Schmalz in 1849 had made similar observations. Curiously, Rinne's report was also lost until Lucae (1880), Emerson (1884), and Schwabach (1885) confirmed the value of his work, since when it has retained the name of Rinne but not of Polansky.

\section{Vibration sense}

The concept of proprioceptive function, developed by Landry, Bell, Bastian, Ferrier, and others in the 19th century, advanced at the turn of the 20th century, and was further advanced by Sherrington ${ }^{8}$ and later Haldane": "The receptor organs are those parts of the living organism which are specially sensitive to the changes going on around them. Some of them are affected by the changes going on inside the body in muscles and joints and in the organ of balance (proprioceptors), others by the changes taking place in the world outside (exteroceptors)."

Kühne showed the presence of proprioceptive receptors in muscles ("Kühne's spindles") in 1862-3.

In Gowers' textbook of $1888^{10}$ we find tactile, thermal, and pain sensory tests but he omits the sense of vibration. It was not until the beginning of the 20th century that tuning forks were applied to bony prominences and muscles to elicit "vibration sense" which was recognised as a crude method of testing neural pathways similar to those used in proprioception. Vibration was but repeated touch. ${ }^{11}$

Continued on page 733 